\title{
Genomic differences between black and white patients implicate a distinct immune response to papillary renal cell carcinoma
}

\author{
David J. Paulucci ${ }^{1}$, John P. Sfakianos ${ }^{1}$, Anders J. Skanderup ${ }^{2}$, Kathleen Kan ${ }^{1}$, Che- \\ Kai Tsao ${ }^{3}$, Matthew D. Galsky ${ }^{3}$, A. Ari Hakimi ${ }^{4}$, Ketan K. Badani ${ }^{1}$ \\ ${ }^{1}$ Department of Urology, Icahn School of Medicine at Mount Sinai Hospital, New York, NY, USA \\ ${ }^{2}$ Computational Biology Program, Sloan Kettering Institute for Cancer Research, Memorial Sloan Kettering Cancer Center, \\ New York, NY, USA \\ ${ }^{3}$ Department of Medicine, Division of Hematology/Oncology, Tisch Cancer Institute, Icahn School of Medicine at Mount Sinai, \\ New York, NY, USA \\ ${ }^{4}$ Department of Surgery-Urology Service, Memorial Sloan Kettering Cancer Center, New York, NY, USA \\ Correspondence to: Ketan K. Badani, email: Ketan.Badani@mountsinai.org \\ Keywords: papillary renal cell carcinoma, racial disparities, immune system signaling, targeted therapy, immune response \\ Received: May 03, 2016 \\ Accepted: November 22, 2016 \\ Published: December 23, 2016
}

\section{ABSTRACT}

Significant disparities in survival, incidence and possibly response to current therapies exist between black and white patients with renal cell carcinoma (RCC). Recent genomic evidence to account for these disparities has been reported for clear cell RCC. However, racial disparities at the genomic level for papillary RCC (pRCC) which is a genetically distinct and less responsive histologic subtype of RCC have not been reported. Using The Cancer Genome Atlas (TCGA) data, the present study assessed gene-level expression, somatic mutation and pathway differences between 58 black and 58 white patients with pRCC propensity matched on age, gender and pathologic $T$ stage. Distinct tumor biology with differential expression patterns were observed in black vs. white patients with pRCC. Specifically, significance analysis of microarrays was applied to TCGA gene expression data and identified 163 genes and 120 genes overexpressed in black and white patients, respectively (FDR q<0.05). Gene Set Enrichment Analysis identified 62 gene sets enriched $(p<0.10)$ in blacks. Enrichment of immune immune system pathways were noted in black patients. These included the B cell receptor signaling pathway, the NOD-like receptor signaling pathway and genes involved in defensins. The VEGF pathway was also more significant in black patients. CRYBB2, a gene associated with the WNT pathway was overexpressed in Black patients. While our data requires validation, these findings suggest that race may have implications for distinct immune responses to cancer and that the use of immunotherapies, and VEGFR inhibitors to target these pathways may improve survival in black patients with advanced pRCC.

\section{INTRODUCTION}

The 5 year survival rate for the estimated 61,560 new cases of kidney cancer in 2015 is $73 \%$ [1]. Survival from kidney cancer is heavily dependent on the stage of disease with a 5 year survival rate of $12 \%$ for patients with metastatic RCC [1]. Strong evidence also exists to suggest that survival from RCC is dependent on race with studies showing worse 5 year overall survival for black vs. white patients (68.0\% vs. $72.6 \%)$, despite black patients being more likely to present with localized RCC [2-7]. Specifically in a recent study by Rose et al. using the National Cancer Database, it was found that black compared to white patients with stage IV RCC before and during the targeted therapy era had worse survival irrespective of age, comorbidities, income, insurance, treatment facility type, grade, histology, receipt of nephrectomy and receipt of systemic therapy [7].

While lack of access to quality health care, lower rates of nephrectomy, greater use of alcohol, tobacco and higher rates of obesity and hypertension are suggested to underlie disparities in survival and incidence between black and white patients $[3,4,6,8]$, recent reports have suggested that differences in tumor biology of RCC may 
also contribute to disparities in survival between black and white patients $[7,9]$. Particularly in a study of black and white patients with clear cell RCC (ccRCC) by Krishnan et al. using both The Cancer Genome Atlas (TCGA) data set and a validation set, it was found that VHL mutations occurred at a lower frequency in black patients and also that vascular endothelial growth factors (VEGF) and hypoxia-inducible factor (HIF) pathways were upregulated less in black patients [9].

Racial disparities in survival also appear to be regardless of histology as evidenced by worse survival for black patients in the study by Rose et al in a predominantly ccRCC cohort and by Pai et al. in a predominantly pRCC cohort $[7,10]$. While the study by Krishnan et al. offers strong genomic evidence as to why survival is worse in black patients despite the proliferation of VEGF-targeted therapies, it is limited to ccRCC and includes no patients with papillary RCC (pRCC) [9].

No studies have characterized genomic differences between black and white patients with pRCC; a genetically and phenotypically distinct form of RCC that occurs at a higher rate in black patients [2]. pRCC vs. ccRCC is specifically characterized by MET mutations and gains of chromosomes $7,12,16$ and 17 as possible drivers $[11,12]$ whereas losses of heterozygosity of chromosome $3 \mathrm{p}$ and inactivating mutations of the VHL gene characterize ccRCC [13]. Additionally, while pRCC occurs less frequently than ccRCC [2] and is also less likely to metastasize than ccRCC [14], pRCC vs. ccRCC when in the presence of vena cava thrombus is worse [15] and yields lower response rates to current targeted molecular therapies (e.g., sunitinib, temsirolimus) $[16,17]$.

The current study therefore sought to identify genelevel expression, pathway and non-silent somatic mutation differences between black and white patients with pRCC.

\section{RESULTS}

\section{Demographic, clinical, pathologic outcomes and survival}

Demographic, clinical and pathologic features for the pre and post propensity matched cohorts are presented in Table 1. Among the 58 black patients and 58 white patients in post-propensity score matched cohort, no differences were found in any demographic, clinical or pathologic features including age $(\mathrm{p}=.536)$ and pathologic stage $(\mathrm{p}=.937)$.

In the post-propensity matched cohort, black and white patients had no differences in overall survival $(\mathrm{HR}=0.47, \mathrm{p}=.336)$ and cancer-specific survival $(\mathrm{HR}=1.00$, $\mathrm{p}=.999)$.

\section{Supervised whole genome expression analysis}

Significance analysis of Microarrays (SAM) analysis identified 283 differentially expressed genes after false discovery rate correction (FDR q<.05) (Figure 1). 163 genes were overexpressed in black patients and 120 genes were overexpressed in white patients. For the propensity matched cohort, all genes differentially expressed with corresponding 2-fold or greater change are presented in Table 2. All genes differentially expressed can be identified in Supplementary Table S1. Genes overexpressed in black vs. white patients with a fold change $\geq 2$ included DHX40P1 (Fold Change $(\mathrm{FC})=2.46$ $\mathrm{E} 8)$, ATCAY $(\mathrm{FC}=2.46 \mathrm{E} 8)$, TREML4 $(\mathrm{FC}=2.25 \mathrm{E} 8)$, LOC100124692 (FC=1.52 E8), GSTM1 (FC=42.33), FCN2 (FC=4.92), GRIN21 (FC=4.76), FAM153A $(\mathrm{FC}=4.66), \mathrm{UBD}(\mathrm{FC}=4.38), \mathrm{CRYBB} 2(\mathrm{FC}=4.37), \mathrm{FLT} 3$ $(\mathrm{FC}=3.93)$, FAM70A ( $\mathrm{FC}=3.41), \mathrm{MGAM}(\mathrm{FC}=3.35)$, LRRC55 (FC=3.33), CCL3L11 $(\mathrm{FC}=3.12), \quad \mathrm{SOX} 30$ $(\mathrm{FC}=2.84)$, JAKMIP1 $(\mathrm{FC}=2.82)$ and $\mathrm{GSTT} 2(\mathrm{FC}=2.75)$ among others.

\section{Pathway analysis}

We identified 62 genes sets that were enriched in black patients (nominal $\mathrm{p}<0.10$ ). The complete list of gene sets is shown in Supplementary Table S2. GSEA identified several immune related pathways enriched in black patients including the B cell receptor signaling pathway $(\mathrm{p}=.097)$, NOD-like receptor signaling pathway $(\mathrm{p}=.054)$, and genes involved in defensins $(p=.042)$ (Figure 2). Furthermore, enrichment of the VEGF pathway; $p=0.040$, was identified in black patients (Figure 2).

\section{Gene-level mutations}

Results from gene-level somatic mutation rate comparisons between black and white patients are presented in Table 3. MUC4 was mutated at a higher rate in black patients $(26.7 \%$ vs. $7.3 \%, \mathrm{p}=.044)$ and PCDHGC5 was mutated at a higher rate in white patients $(17.1 \%$ vs. $0.0 \%, \mathrm{p}=.018)$.

\section{DISCUSSION}

Previous studies have shown that survival for black vs. white patients with RCC is worse [7, 10]. While previous reports suggest that factors including a higher prevalence of hypertension, smoking, alcohol use and lack of access to care underlie this survival disparity [3, $4,6,8]$, this survival disparity may also be explained by the present study's identification of distinct tumor biology between black and white patients with papillary RCC [9]. Specifically in the present study's supervised whole genome expression analysis between 58 black and 58 white propensity score matched patients with pRCC, we identified a distinct tumor biology as demonstrated by enrichment of immune related pathways including the $B$ cell receptor signaling pathway, NOD-like receptor signaling pathway, and genes involved in defensins, 
Table 1: Clinical characteristics and pathologic features between black and white pRCC patients

\begin{tabular}{|c|c|c|c|c|c|c|}
\hline & \multicolumn{3}{|c|}{ Pre-Propensity Matched Cohort } & \multicolumn{3}{|c|}{ Propensity Matched Cohort } \\
\hline & Black Patients & White Patients & P Value & Black Patients & White Patients & $P$ Value \\
\hline Patients & $58(22.8 \%)$ & $196(77.2 \%)$ & & $58(50.0 \%)$ & $58(50.0 \%)$ & \\
\hline Age & $59.0(50.0-66.5)$ & $63.0(55.0-71.0)$ & .018 & $59.0(50.0-66.5)$ & $59.5(52.3-66.8)$ & .536 \\
\hline Male & $37(63.8 \%)$ & $145(74.0 \%)$ & .131 & $37(63.8 \%)$ & $44(75.9 \%)$ & .157 \\
\hline Hispanic or Latino & $1(1.9 \%)$ & $9(5.1 \%)$ & .460 & $1(1.9 \%)$ & $1(1.8 \%)$ & $>.999$ \\
\hline BMI & $30.4(25.5-33.8)$ & $28.0(25.5-31.8)$ & .115 & $30.4(25.5-33.8)$ & $27.4(25.1-29.5)$ & .029 \\
\hline $\begin{array}{l}\text { Karnofsky } \\
\text { Performance Score }\end{array}$ & $90(90-100)$ & $100(90-100)$ & .477 & $90(90-100)$ & $100(90-100)$ & .658 \\
\hline USA Case & $48(100.0 \%)$ & $152(89.9 \%)$ & .016 & $48(100.0 \%)$ & $41(82.0 \%)$ & .003 \\
\hline \multicolumn{7}{|l|}{ Subtype } \\
\hline Type 1 & $20(60.6 \%)$ & $51(44.7 \%)$ & .108 & $20(60.6 \%)$ & $18(50.0 \%)$ & .377 \\
\hline Type 2 & $13(39.4 \%)$ & $63(55.3 \%)$ & & $13(39.4 \%)$ & $18(50.0 \%)$ & \\
\hline $\begin{array}{l}\text { Year of Initial } \\
\text { Pathologic } \\
\text { Diagnosis }\end{array}$ & $2011(2009-2012)$ & $2010(2008-2012)$ & .086 & $2011(2009-2012)$ & $2010(2008-2012)$ & .148 \\
\hline Smoking Status & & & .544 & & & .376 \\
\hline Never & $21(40.4 \%)$ & $80(49.1 \%)$ & & $21(40.4 \%)$ & $21(44.7 \%)$ & \\
\hline Former & $22(42.3 \%)$ & $60(36.8 \%)$ & & $22(42.3 \%)$ & $13(29.8 \%)$ & \\
\hline Current & $9(17.3 \%)$ & $23(14.1 \%)$ & & $9(17.3 \%)$ & $12(25.5 \%)$ & \\
\hline Tumor Laterality & & & .103 & & & .469 \\
\hline Right & $28(49.1 \%)$ & $85(43.4 \%)$ & & $28(49.1 \%)$ & $23(39.7 \%)$ & \\
\hline Left & $27(47.4 \%)$ & $110(56.1 \%)$ & & $27(47.4 \%)$ & $34(58.6 \%)$ & \\
\hline Bilateral & $2(3.5 \%)$ & $1(0.5 \%)$ & & $2(3.5 \%)$ & $1(1.7 \%)$ & \\
\hline \multicolumn{7}{|l|}{ Clinical } \\
\hline $\mathrm{T} 1$ & $36(72.0 \%)$ & $96(73.3 \%)$ & & $36(72.0 \%)$ & $25(69.4 \%)$ & \\
\hline $\mathrm{T} 2$ & $10(20.0 \%)$ & $15(11.5 \%)$ & .186 & $10(20.0 \%)$ & $8(22.2 \%)$ & .937 \\
\hline $\mathrm{T} 3$ & $4(8.0 \%)$ & $20(15.3 \%)$ & & $4(8.0 \%)$ & $3(8.3 \%)$ & \\
\hline N1 & $3(5.2 \%)$ & $10(7.5 \%)$ & .294 & $3(5.2 \%)$ & $4(6.9 \%)$ & .572 \\
\hline \multicolumn{7}{|l|}{ Pathologic } \\
\hline Tumor Size & $4.5(3.0-6.5)$ & $4.0(2.8-6.0)$ & .292 & $4.5(3.0-6.5)$ & $4.8(2.7-8.5)$ & .677 \\
\hline Tumor Weight & $208.5(120.8-350.0)$ & $200(136.5-300.0)$ & .763 & $208.5(120.8-350.0)$ & $200.0(160.0-323.0)$ & .933 \\
\hline $\mathrm{T} 1$ & $40(69.0 \%)$ & $137(69.9 \%)$ & & $40(69.0 \%)$ & $36(62.1 \%)$ & \\
\hline $\mathrm{T} 2$ & $12(20.7 \%)$ & $16(8.2 \%)$ & .009 & $12(20.7 \%)$ & $13(22.4 \%)$ & .654 \\
\hline $\mathrm{T} 3$ & $6(10.3 \%)$ & $43(21.9 \%)$ & & $6(10.3 \%)$ & $9(15.5 \%)$ & \\
\hline N1 & $3(5.2 \%)$ & $16(8.2 \%)$ & .578 & $3(5.2 \%)$ & $4(6.9 \%)$ & $>.999$ \\
\hline $\begin{array}{l}\text { Tumor Necrosis } \\
\text { Present }\end{array}$ & $18(31.2 \%)$ & $77(39.3 \%)$ & .290 & $18(31.2 \%)$ & $28(48.3 \%)$ & .068 \\
\hline $\begin{array}{l}\text { Percent of Tumor } \\
\text { Nuclei Present }\end{array}$ & $85 \%(70-90 \%)$ & $85 \%(80-90 \%)$ & .788 & $85 \%(70-90 \%)$ & $87 \%(80-90 \%)$ & .608 \\
\hline
\end{tabular}

For categorical variables, chi square tests performed. Frequencies presented with percentages in parenthesis.

For continuous variables, Mann- Whitney U tests performed. Medians presented with inter-quartile range in parenthesis. 
VEGF and more specifically overexpression of CRYBB2 associated with the WNT signaling pathway in black patients.

The VEGF pathway in particular plays a prominent role in angiogenesis, resistence to therapy and metastases [18-21]. Thus, enrichment of this pathway in black vs. white patients may contribute to worse survival observed in black patients with RCC. Additionally, overexpression of CRYBB2 which is associated with the WNT signaling pathway involved in tumor progression, growth, differentiation and metastases [22, 23] may also contribute to worse survival observed in black patients with RCC.

Our data raises questions regarding racial differences in cancer biology. This is important to consider when executing clinical trials. In RCC trials this is a significant issue. In a study of Nivolumab vs. Everolimus for ccRCC, only $6(0.6 \%)$ of the 821 patients included were black [24]. Similarly in a randomized controlled trial comparing Cabozantinib and Everolimus for advanced RCC, 658 patients were included in the study of which $532(80.1 \%)$ patients were white only $9(1.4 \%)$ patients were black [25]. Also in a randomized controlled trial Pazopanib vs. placebo of 435 patients, $1(0.2 \%)$ patient was black and $374(85.9 \%)$ patients were white [26]. Among the studies of targeted therapy and immunotherapy in pRCC in which race is reported, $11 \%(n=12 / 108)$ is the highest proportion of black patients reported for any study [27, 28]. With our demonstration of distinct pRCC biology and Krishnan et al.'s demonstration of distinct ccRCC biology between black and white patients, it is likely inaccurate to apply findings within predominantly white cohorts to black patients with RCC for either histologic subtype. Additionally, efforts should be made to ensure that trials are set up in geographically accessible areas and that black patients with RCC are made aware of these trials.

Enrichment of the VEGF pathway may predict increased responsiveness of black patients with advanced pRCC to VEGF receptor (VEGFR) inhibitors. Currently, positive upstream regulators of the $\mathrm{PI} 3 \mathrm{~K} / \mathrm{AKT} / \mathrm{mTOR}$ signaling pathway including VEGFRs and their ligands are primary targets in the treatment of advanced RCC using VEGFR and mTOR inhibitors including sunitinib, temsirolimus, everolimus, bevacizumab and sorafenib among others [29, 30]. However, activity for these TMTs is lower for advanced pRCC vs. ccRCC $[16,17]$ and the NCCN guidelines recommend clinical trial enrollment as the preferred treatment option for patients with advanced pRCC [31]. Specifically in the treatment of locally advanced or metastatic pRCC, progression-free survival for sunitinib, everolimus and temsirolimus ranged from 1.6-8.1 months, 3.4-5.5 months and 5.9 months, respectively. [27-28, 32-36].

While results from these studies demonstrate poor efficacy of VEGFR and mTOR inhibitors for advanced pRCC overall, our finding of VEGF enrichment in black patients suggests increased responsiveness of these therapies particularly in black patients with advanced pRCC. Distinct tumor biology has previously been identified in ccRCC; particularly with less up regulation of HIF and VEGF pathways in black patients to suggest a lower response to VEGF targeted therapies among black patients with ccRCC. However, pRCC is a genetically distinct form of RCC driven by MET mutations and gains of chromosomes 7,12,16 and 17 as possible drivers [11, 12]; and in the present study, enrichment of VEGF pathway conversely suggests increased responsiveness of VEGFR tartgeted therapies among black patients with pRCC.

Increased responsiveness in black patients with the use of targeted therapies for these pathways should be validated and the use of VEGFR therapies in the adjuvant or first line setting should be explored in future clinical trials for advanced pRCC. Additionally, while the number of patients in randomized trials for pRCC vs. ccRCC is already low and the number of black vs. white patients in trials for RCC is even lower, multi-institutional efforts to pool data should be undertaken to analyze whether trials

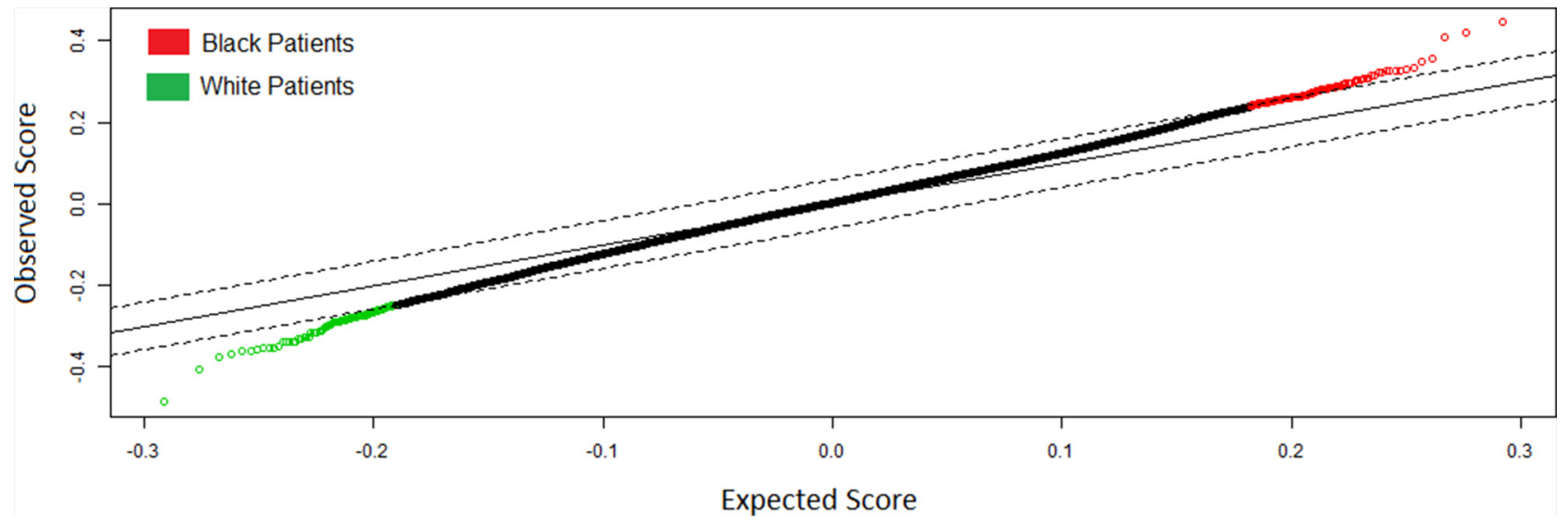

Figure 1: Significance Analysis of Microarrays Plot of Genes Differentially Expressed $(q<.05)$ Between Black and White Patients with Papillary Renal Cell Carcinoma. 
Table 2: Genes differentially overexpressed in black compared to white pRCC patients with a fold-change $\geq 2$

\begin{tabular}{|c|c|c|}
\hline Gene Overexpressed & Fold-Change & q-value \\
\hline DHX40P1 & $2.46 \mathrm{E} 8$ & 0.011 \\
\hline ATCAY & $2.46 \mathrm{E} 8$ & 0.031 \\
\hline TREML4 & $2.25 \mathrm{E} 8$ & 0.036 \\
\hline LOC100124692 & $1.52 \mathrm{E} 8$ & 0.036 \\
\hline GSTM1 & 42.23 & 0.05 \\
\hline FCN2 & 4.92 & 0 \\
\hline GRIN2A & 4.76 & 0.031 \\
\hline FAM153A & 4.66 & 0.043 \\
\hline UBD & 4.38 & 0 \\
\hline CRYBB2 & 4.37 & 0 \\
\hline FLT3 & 3.93 & 0 \\
\hline FAM70A & 3.41 & 0.018 \\
\hline MGAM & 3.35 & 0.05 \\
\hline LRRC55 & 3.33 & 0 \\
\hline CCL3L1 & 3.12 & 0.026 \\
\hline SOX30 & 2.84 & 0.018 \\
\hline JAKMIP1 & 2.82 & 0.041 \\
\hline GSTT2 & 2.75 & 0.036 \\
\hline PRSS45 & 2.57 & 0.031 \\
\hline GRAP2 & 2.37 & 0.045 \\
\hline EMR1 & 2.34 & 0 \\
\hline CA8 & 2.28 & 0.031 \\
\hline CXCL9 & 2.27 & 0.018 \\
\hline TARP & 2.22 & 0.043 \\
\hline IRF4 & 2.22 & 0.043 \\
\hline CXCL10 & 2.15 & 0.036 \\
\hline HLA-DPB2 & 2.11 & 0.036 \\
\hline CPT1C & 2.11 & 0.05 \\
\hline P2RY10 & 2.1 & 0.046 \\
\hline LPL & 2.08 & 0.05 \\
\hline CHST1 & 2.07 & 0 \\
\hline PDE2A & 2.07 & 0 \\
\hline SCUBE1 & 2.02 & 0.047 \\
\hline FAM162B & 2.01 & 0.011 \\
\hline
\end{tabular}

* No overexpressed genes in White patients had a fold change $\geq 2$. 
utilizing VEGFR therapies are producing a favorable response in black patients with advanced pRCC. Such efforts would serve as a route to reduce survival disparities between black and white patients with RCC.

In addition, enrichment of immune related pathways involved in B cell receptor signaling, NOD-like receptor signaling, genes involved in defensins and more specifically overexpression of genes involved in immunerelated pathways and processes (RHOH, TREML4, FCN2, CCL3L1, GRAP2, CXCL9, TARP, IRF4, CXCL10, CXCL11, IFITM1, LAMP3, GATA2, etc.) were found in black patients. To further understand the relationship between increased immune activity in tumors of black patients and racial outcome disparities in RCC, future studies are needed. An increased immune response to pRCC in black vs. white patients would suggest that enrichment of the VEGF pathway and overexpression of genes involved in the WNT pathway in addition to other pathologic factors (i.e., hypertension, smoking status, access to care) are underlying worse outcomes for black patients with RCC. Nonetheless, overactivity of immune related pathways in black patients implicates a greater response and larger role for immunotherapies in the first line or adjuvant setting for these patients.

Nivolumab (a PD-1 immune checkpoint inhibitor) compared to Everolimus (an mTOR inhibitor) has recently been shown to result in a greater objective response rate (25\% vs. $5 \%$ ) and longer overall survival in ccRCC; however no patients enrolled had $\mathrm{pRCC}$ [24]. In a recent case report by Geynisman et al. a rapid response to Nivolumab was observed in a patient with metastatic pRCC with sarcomatoid and rhaboid features [36]. While this patient only received Nivolumab due to his declining performance status and development of subcutaneous lesions, future studies of Nivolumab in the first-line setting or adjuvant setting should enroll patients with pRCC as a favorable response may be observed overall and particularly in black patients.

Additionally, a study of interferon-alfa showed progression-free survival for interferon to be 2.1 months for $\mathrm{pRCC}$ [37]. While the use of interferon for $\mathrm{pRCC}$ evidently yields poor oncologic outcome, its use for advanced pRCC should be further explored as should the use of interferon before VEGF therapies which is being explored for ccRCC [38] since black patients may be more likely to experience an oncologic benefit. Multi-institutional efforts to pool data from previous and current trials of pRCC should also be undertaken to assess whether there is increased efficacy of immunotherapies including interferon and IL-2 in black patients with advanced pRCC. Such studies would allow for a better understanding of the clinical efficacy of these drugs in black patients for future studies.

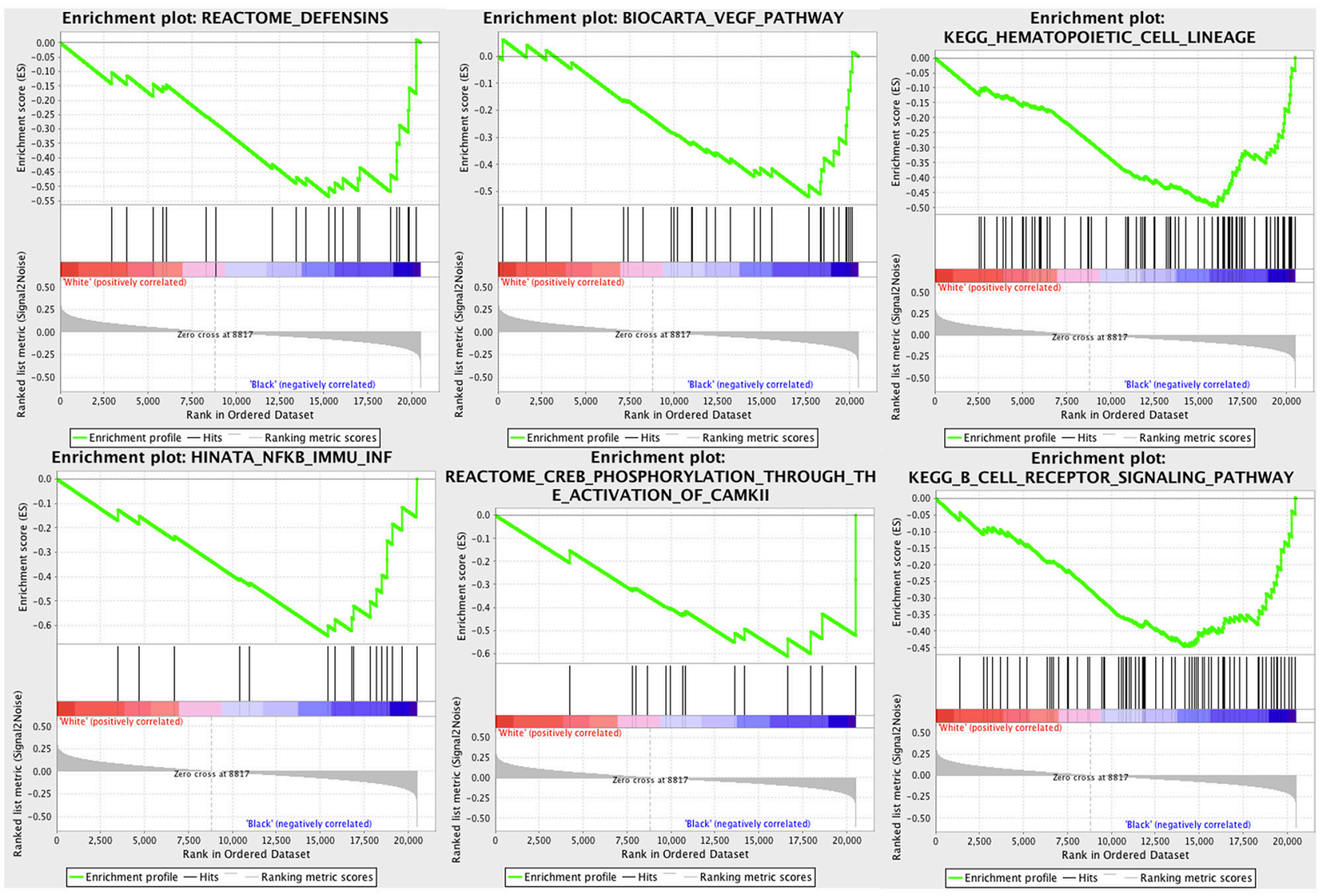

Figure 2: Gene sets overrepresented in black patients with pRCC. $-\log 10$ of p-values are shown in the different subsets. 
Table 3: Comparison of gene-level non silent somatic mutations between black and white papillary RCC patients

\begin{tabular}{|c|c|c|c|}
\hline Gene & Black Patients & White Patients & P Value \\
\hline & $41(57.7 \%)$ & $30(42.3 \%)$ & \\
\hline abParts & $10(24.4 \%)$ & $4(13.3 \%)$ & .247 \\
\hline DDX12P & $5(12.2 \%)$ & $6(20.0 \%)$ & .509 \\
\hline FLJ36000 & $5(12.2 \%)$ & $5(16.7 \%)$ & .733 \\
\hline FRG1B & $2(4.9 \%)$ & $3(10.0 \%)$ & .644 \\
\hline CROCCP2 & $5(12.2 \%)$ & $4(13.3 \%)$ & $>.999$ \\
\hline MUC4 & $3(7.3 \%)$ & $8(26.7 \%)$ & .044 \\
\hline MGC70870 & $13(31.7 \%)$ & $6(20.0 \%)$ & .271 \\
\hline MST1P2 & $5(12.2 \%)$ & $5(16.7 \%)$ & .733 \\
\hline PCDHGC5 & $7(17.1 \%)$ & $0(0.0 \%)$ & .018 \\
\hline TTN & $4(9.8 \%)$ & $5(16.7 \%)$ & .479 \\
\hline
\end{tabular}

Chi square tests of Independence of Fisher's Exact Tests performed. Frequencies presented with percentages in parenthesis.

CRYBB2 associated with the WNT pathway was overexpressed in Black patients and other studies in colon and breast cancer have shown promising results for targeting of the WNT pathway with small molecules, peptides and blocking antibodies [23].

Although we propensity score matched black and white patients on age, gender and pathologic $\mathrm{T}$ stage, these findings are limited by unavailable/missing data and a relatively small sample size. Specifically, lack of data within the TCGA on hypertension, alcohol use, BMI $(n=65)$ and pRCC subtype $(n=107)$ limit us from attributing these genelevel expression differences to race alone. Additionally, the limited sample size of this study and the lack of a validation data set confounds the generalizability of these findings and highlights the need for independent validation of these results for reliability and validity.

An additional limiting factor is that we are unable to show a survival difference in this study, perhaps due to the low sample size. While the majority of patients in the study by Pai et al. showing worse survival for black patients had pRCC, this study was not exclusive to pRCC and included several patients with chromophobe and collecting duct RCC [10]. No studies have showed a survival disadvantage based on race specifically for $\mathrm{pRCC}$ after adjusting for confounders.

An additional limitation of this study is limited genelevel mutation data for black $(n=41)$ and white $(n=30)$ patients. Compared to previous reports of a $12 \%$ mutation rate for MET, MET in the current study was not one of the most commonly mutated genes included for analysis, thus demonstrating the underestimation of MET mutations resulting from a low sample size [11-12]. A limitation of this study is that pRCC TCGA data is based on primary nephrectomy specimens $[39,40]$ and may limit the ability of these findings to be applied to predict response to metastatic pRCC treatments for black and white patients since primary metastatic vs. primary nephrectomy RCC specimens have significantly different expression profiles [41].

A primary confounding factor to our study is intratumor heterogeneity since the TCGA relies on a single-site sample of each specimen for sequencing [42]. Specifically distinct subclones with distinct mutation and expression within the same tumor may have provided us with different outcomes depending on the sample of the tumor sequenced. It is also unknown whether increased representation of $\mathrm{CpG}$ island methylator phenotype tumors which yield worse outcomes [43] were also overrepresented in black patients. This should be explored in future studies as this may help to further explain racial disparities in RCC.

We report the first study to compare the genomic landscape between black and white patients with pRCC. Distinct tumor biology was identified with differential expression of 283 genes and enrichment of the VEGF pathway, immune system pathways and overexpression of CRYBB2 associated with the WNT pathway in black patients. Thus, it is likely inaccurate to apply results from RCC biomarker and targeted therapy studies of predominantly white patients to the underrepresented black population. Our data requires validation and further elucidation in pre-clinical models, but these results may predict an increased immune response to the tumor in black patients and also an increased response to immunotherapies and or VEGFR inhibitors for black patients with advanced pRCC. Future studies and personalized medicine approaches relying on combination or sole forms of therapy with the use of immunotherapies and targeted therapies (VEGFR) may serve as a route to improve survival in black patients with pRCC. This should 
be explored in pre-clinical models and in clinical trials in the first-line or adjuvant setting for advanced and high-risk localized pRCC.

\section{MATERIALS AND METHODS}

The present retrospective study relied on the University of California Santa Cruz Genome (UCSC) Browser to download publicly available gene-level non-silent somatic mutation data (nonsense, missense, frame-shift indels, splice site mutations, stop codon readthrought, change of start codon, inframe indels) relied on Firewbrowse to download RNASeq gene expression and clinical pRCC TCGA data [44]. The non-silent somatic mutation data used is data that the UCSC genome browser downloaded directly from the TCGA's data coordinating center and has processed at UCSC into their data repository. Calls for the broad curated mutation data were generated at the Broad Institute Genome Sequencing Center using the MutDect method. Clinical data and raw read count RNASeq expression data is direct and original TCGA data that Firebrowse (a portal of archived TCGA data hosted by the Broad Institute of MIT and Harvard) archives for public access and download.

Patients were excluded from the study if they had the following criteria: Asian or American Indian/Alaskan Native race, no race data available, metastatic disease, missing gene expression data, missing pathologic stage data. We included 254 (58 black, 196 white) of 291 patients with an initial diagnosis of pRCC from 2001-2013.

To reduce the confounding influence of selection bias in our gene-level analyses between black and white patients, we applied nearest-neighbor 1 to 1 propensity score matching on the cohort. While the use of a 1 to 1 vs. 2 to 1 propensity score matching ratio may result in a minor decrease in power and precision, this ratio results in less bias [45]. Patients were matched on age and gender in addition to pathologic T stage. Propensity score matching was conducted using the MatchIt package in R Studio version 0.98.1091 [46].

For the propensity matched cohort of 58 black and 58 white patients, we utilized the SAMseq package in $\mathrm{R}$ and performed significance analysis on microarray analysis on raw read count RNA-Seq gene expression data of 20,530 genes using 1000 repeated permutations and false discovery rate correction $(\mathrm{q}<.05)$.

In a subset of propensity matched $\mathrm{pRCC}$ patients with gene-level mutation and paired clinical data available $(n=71)$, rates of non-silent somatic gene-level mutations were compared between 41 (57.7\%) black and 30 (42.3\%) white patients. Genes compared included genes identified as the most top 10 most frequently mutated in the dataset (i.e., abParts, DDX12P, FJL36000, FRG1B, CROCCP2, MUC4, MGC70870, MST1P2, PCDHGC5, TTN). Somatic mutation rates were compared using chi-squared tests of independence and fisher's exact tests.
For the overall cohort and for the propensity matched cohort, age, gender, BMI, Type 1 vs. Type 2 pRCC, clinical and pathologic TNM stages were compared between black and white patients. Also compared between groups were year of initial pathologic diagnosis, history of malignancy, history of neoadjuvant therapy, history of smoking, targeted molecular therapy use and use of adjuvant radiation therapy. Pathologic and clinical stage were treated in an ordinal fashion for analysis (i.e., $\mathrm{T} 1=1$, $\mathrm{T} 2=2$, $\mathrm{T} 3=3, \mathrm{~T} 4=4$ ) since $\mathrm{a}, \mathrm{b}$ and $\mathrm{c}$ sub-classification within staging was not available for all patients.

Overall survival (OS) and cancer specific survival (CSS) were compared in univariable cox proportion hazards models. Death was defined as related to renal cancer according to a previously defined method if the patient had clinical M1, a tumor present at the time of death or if composite tumor status was unavailable [47, 48].

All other continuous and categorical variables were compared using Mann-Whitney U tests and chi-squared tests of independence respectively. All statistical analysis was conducted using R Studio version 3.1.3 and SPSS Version 20.0.

Gene Set Enrichment Analysis (GSEA) [49] to evaluate differential activity of pathways and gene sets in white and black patient groups. Changes in gene expression between the two patient groups were evaluated using a t-statistic. 1077 gene sets from MSigDB v. 5.1 (using the c2 "curated pathways", c6, and "Hallmark" collections) were evaluated for differential expression. To account for gene-gene correlations in the enrichment analysis, GSEA $P$-values were computed with respect to a null distribution obtained from 1000 randomizations of the patient-phenotype labels, and false discovery rates were estimated by the GSEA software.

\section{CONFLICTS OF INTEREST}

The authors have no conflict of interest to declare.

\section{REFERENCES}

1. Siegel RL, Miller KD and Jemal A. Cancer statistics, 2015. CA Cancer J Clin. 2015; 65:5-29.

2. Chow WH, Shuch B, Linehan WM and Devesa SS. Racial disparity in renal cell carcinoma patient survival according to demographic and clinical characteristics. Cancer. 2013; 119:388-394.

3. Vaishampayan UN, Do H, Hussain M and Schwartz K. Racial disparity in incidence patterns and outcome of kidney cancer. Urology. 2003; 62:1012-1017.

4. Lipworth L, Tarone RE and McLaughlin JK. Renal cell cancer among African Americans: an epidemiologic review. BMC Cancer. 2011; 11:133.

5. Stafford HS, Saltzstein SL, Shimasaki S, Sanders C, Downs TM and Sadler GR. Racial/ethnic and gender disparities in 
renal cell carcinoma incidence and survival. J Urol. 2008; 179:1704-1708.

6. Berndt SI, Carter HB, Schoenberg MP and Newschaffer CJ. Disparities in treatment and outcome for renal cell cancer among older black and white patients. J Clin Oncol. 2007; 25:3589-3595.

7. Rose TL, Deal AM, Krishnan B, Nielsen ME, Smith AB, Kim WY and Milowsky MI. Racial disparities in survival among patients with advanced renal cell carcinoma in the targeted therapy era. Cancer. 2016.

8. Lin J, Zahm SH, Shriver CD, Purdue M, McGlynn KA and Zhu K. Survival among Black and White patients with renal cell carcinoma in an equal-access health care system. Cancer Causes Control. 2015; 26:1019-1026.

9. Krishnan B, Rose TL, Kardos J, Milowsky MI and Kim WY. Intrinsic Genomic Differences Between African American and White Patients With Clear Cell Renal Cell Carcinoma. JAMA Oncol. 2016.

10. Pai A, Brunson A, Brown M, Pan CX and Lara PN. Evolving epidemiologic trends in nonclear cell renal cell cancer: an analysis of the California Cancer Registry. Urology. 2013;82:840-845.

11. Marsaud A, Dadone B, Ambrosetti D, Baudoin C, Chamorey E, Rouleau E, Lefol C, Roussel JF, Fabas T, Cristofari G, Carpentier X, Michiels JF, Amiel J and Pedeutour F. Dismantling papillary renal cell carcinoma classification: The heterogeneity of genetic profiles suggests several independent diseases. Genes Chromosomes Cancer. 2015; 54:369-382.

12. Kovac M, Navas C, Horswell S, Salm M, Bardella C, Rowan A, Stares M, Castro-Giner F, Fisher R, de Bruin EC, Kovacova M, Gorman M, Makino S, Williams J, Jaeger E, Jones A, et al. Recurrent chromosomal gains and heterogeneous driver mutations characterise papillary renal cancer evolution. Nat Commun. 2015; 6:6336.

13. Storkel S, Eble JN, Adlakha K, Amin M, Blute ML, Bostwick DG, Darson M, Delahunt B and Iczkowski K. Classification of renal cell carcinoma: Workgroup No. 1. Union Internationale Contre le Cancer (UICC) and the American Joint Committee on Cancer (AJCC). Cancer. 1997; 80:987-989.

14. Leibovich BC, Lohse CM, Crispen PL, Boorjian SA, Thompson RH, Blute ML and Cheville JC. Histological subtype is an independent predictor of outcome for patients with renal cell carcinoma. J Urol. 2010; 183:1309-1315.

15. Tilki D, Nguyen HG, Dall'Era MA, Bertini R, Carballido JA, Chromecki T, Ciancio G, Daneshmand S, Gontero P, Gonzalez J, Haferkamp A. Impact of histologic subtype on cancer-specific survival in patients with renal cell carcinoma and tumor thrombus. European urology. 2014;66:577-583.

16. Motzer RJ, Bacik J, Mariani T, Russo P, Mazumdar M and Reuter V. Treatment outcome and survival associated with metastatic renal cell carcinoma of non-clear-cell histology. J Clin Oncol. 2002; 20:2376-2381.
17. Sankin A, Hakimi AA, Hsieh JJ and Molina AM. Metastatic non-clear cell renal cell carcinoma: an evidence based review of current treatment strategies. Front Oncol. 2015; 5:67.

18. Carmeliet P. VEGF as a key mediator of angiogenesis in cancer. Oncology. 2005 Nov 23;69:4-10.

19. Ishigami SI, Arii S, Furutani M, Niwano M, Harada T, Mizumoto M, Mori A, Onodera H, Imamura M. Predictive value of vascular endothelial growth factor (VEGF) in metastasis and prognosis of human colorectal cancer. British journal of cancer. 1998 Nov;78:1379.

20. Roskoski R. Vascular endothelial growth factor (VEGF) signaling in tumor progression. Critical reviews in oncology/hematology. 2007 Jun 30;62:179-213.

21. Su JL, Yen CJ, Chen PS, Chuang SE, Hong CC, Kuo IH, Chen HY, Hung MC, Kuo ML. The role of the VEGF-C/ VEGFR-3 axis in cancer progression. British journal of cancer. 2007 Feb 26;96:541-5.

22. Polakis P. Wnt signaling in cancer. Cold Spring Harbor perspectives in biology. 2012 May 1;4:a008052.

23. Anastas JN, Moon RT. WNT signalling pathways as therapeutic targets in cancer. Nature Reviews Cancer. 2013; 13:11-26.

24. Motzer RJ, Escudier B, McDermott DF, George S, Hammers HJ, Srinivas S, Tykodi SS, Sosman JA, Procopio G, Plimack ER, Castellano D, Choueiri TK, Gurney H, Donskov F, Bono P, Wagstaff J, et al. Nivolumab versus Everolimus in Advanced Renal-Cell Carcinoma. New Engl J Med. 2015; 373:1803-1813.

25. Choueiri TK, Escudier B, Powles T, Mainwaring PN, Rini BI, Donskov F, Hammers H, Hutson TE, Lee JL, Peltola K, Roth BJ, Bjarnason GA, Geczi L, Keam B, Maroto P, Heng DYC, et al. Cabozantinib versus Everolimus in Advanced Renal-Cell Carcinoma. New Engl J Med. 2015; 373:1814-1823.

26. Sternberg CN, Davis ID, Mardiak J, Szczylik C, Lee E, Wagstaff J, Barrios CH, Salman P, Gladkov OA, Kavina A, Zarba JJ, Chen M, McCann L, Pandite L, Roychowdhury DF and Hawkins RE. Pazopanib in Locally Advanced or Metastatic Renal Cell Carcinoma: Results of a Randomized Phase III Trial. Journal of Clinical Oncology. 2010; 28:1061-1068.

27. Armstrong AJ, Halabi S, Eisen T, Broderick S, Stadler WM, Jones RJ, Garcia JA, Vaishampayan UN, Picus J, Hawkins RE, Hainsworth JD, Kollmannsberger CK, Logan TF, Puzanov I, Pickering LM, Ryan CW, et al. Everolimus versus sunitinib for patients with metastatic non-clear cell renal cell carcinoma (ASPEN): a multicentre, open-label, randomised phase 2 trial. Lancet Oncol. 2016; 17:378-388.

28. Tannir NM, Jonasch E, Albiges L, Altinmakas E, Ng CS, Matin SF, Wang X, Qiao W, Lim ZD, Tamboli P and Rao P. Everolimus versus sunitinib prospective evaluation in metastatic non-clear cell renal cell carcinoma (ESPN): a 
randomized multicenter phase 2 trial. European urology. 2016;69:866-74.

29. Saharinen P, Eklund L, Pulkki K, Bono P and Alitalo K. VEGF and angiopoietin signaling in tumor angiogenesis and metastasis. Trends Mol Med. 2011; 17:347-362.

30. Escudier B, Porta C, Schmidinger M, Algaba F, Patard JJ, Khoo V, Eisen T, Horwich A and Group EGW. Renal cell carcinoma: ESMO Clinical Practice Guidelines for diagnosis, treatment and follow-up. Ann Oncol. 2014; 25:iii49-56.

31. Motzer RJ, Agarwal N, Beard C, Bhayani S, Bolger GB, Carducci MA, Chang SS, Choueiri TK, Hancock SL, Hudes GR, Jonasch E, Josephson D, Kuzel TM, Levine EG, Lin DW, Margolin KA, et al. J Natl Compr Canc Ne. 2011; 9:960-977.

32. Ravaud A, Oudard S, De Fromont M, Chevreau C, Gravis G, Zanetta S, Theodore C, Jimenez M, Sevin E, Laguerre B, Rolland F, Ouali M, Culine S and Escudier B. First-line treatment with sunitinib for type 1 and type 2 papillary renal cell carcinoma: a phase II study (SUPAP) by the French Genitourinary Group (GETUG). Annals of Oncology. 2015; 26:1123-1128.

33. Tannir NM, Plimack E, Ng C, Tamboli P, Bekele NB, Xiao L, Smith L, Lim Z, Pagliaro L, Araujo J and Aparicio A. A phase 2 trial of sunitinib in patients with advanced nonclear cell renal cell carcinoma. European urology. 2012; 62:1013-9.

34. Koh Y, Lim HY, Ahn JH, Lee JL, Rha SY, Kim YJ, Kim TM and Lee SH. Phase II trial of everolimus for the treatment of nonclear-cell renal cell carcinoma. Annals of oncology. $2013 ; 24: 1026-31$.

35. Lee JL, Ahn JH, Lim HY, Park SH, Lee SH, Kim TM, Lee DH, Cho YM, Song C, Hong JH and Kim CS. Multicenter phase II study of sunitinib in patients with non-clear cell renal cell carcinoma. Annals of oncology. 2012; 23:2108-14.

36. Geynisman DM. Anti-programmed cell death protein 1 (PD-1) antibody nivolumab leads to a dramatic and rapid response in papillary renal cell carcinoma with sarcomatoid and rhabdoid features. European urology. 2015; 68:912-4.

37. Dutcher JP, de Souza P, McDermott D, Figlin RA, Berkenblit A, Thiele A, Krygowski M, Strahs A, Feingold J and Hudes G. Effect of temsirolimus versus interferon-alpha on outcome of patients with advanced renal cell carcinoma of different tumor histologies. Med Oncol. 2009; 26:202-209.

38. Artaç M, Çoşkun HŞ, Korkmaz L, Koçer M, Turhal NS, Engin H, Dede İ, Paydaş S, Öksüzoğlu B, Bozcuk H and Demirkazık A. Using Interferon Alfa Before Tyrosine Kinase Inhibitors May Increase Survival in Patients With Metastatic Renal Cell Carcinoma: A Turkish Oncology Group (TOG) Study. Clinical genitourinary cancer. 2016.

39. Trump, Donald. "Commentary on:"Randomized phase III trial of temsirolimus and bevacizumab versus interferon alfa and bevacizumab in metastatic renal cell carcinoma: INTORACT trial.” Rini BI, Bellmunt J, Clancy J, Wang K,
Niethammer AG, Hariharan S, Escudier B. Brian I. Rini, Cleveland Clinic Taussig Cancer Institute, Cleveland, $\mathrm{OH}$; Joaquim Bellmunt, University Hospital del Mar-IMIM, Barcelona, Spain; Jill Clancy, Kongming Wang, Andreas G. Niethammer, Subramanian Hariharan, Pfizer, New York, NY; and Bernard Escudier ...." In Urologic Oncology: Seminars and Original Investigations, vol. 34, no. 5, pp. 250-251. Elsevier, 2016.

40. Linehan WM, Spellman PT, Ricketts CJ, Creighton CJ, Fei SS, Davis C, Wheeler DA, Murray BA, Schmidt L, Vocke CD, Peto M, Al Mamun AAM, Shinbrot E, Sethi A, Brooks S, Rathmell WK, et al. Comprehensive Molecular Characterization of Papillary Renal-Cell Carcinoma. New Engl J Med. 2016; 374:135-145.

41. Sanjmyatav J, Steiner T, Wunderlich H, Diegmann J, Gajda $\mathrm{M}$ and Junker K. A Specific Gene Expression Signature Characterizes Metastatic Potential in Clear Cell Renal Cell Carcinoma. J Urology. 2011; 186:289-294.

42. Gerlinger M, Horswell S, Larkin J, Rowan AJ, Salm MP, Varela I, Fisher R, McGranahan N, Matthews N, Santos CR, Martinez P, Phillimore B, Begum S, Rabinowitz A, SpencerDene B, Gulati S, et al. Genomic architecture and evolution of clear cell renal cell carcinomas defined by multiregion sequencing. Nature Genetics. 2014; 46:225-+.

43. Issa JP. CpG island methylator phenotype in cancer. Nature Reviews Cancer. 2004; 4:988-93.

44. Karolchik D, Barber GP, Casper J, Clawson H, Cline MS, Diekhans M, Dreszer TR, Fujita PA, Guruvadoo L, Haeussler M, Harte RA, Heitner S, Hinrichs AS, Learned K, Lee BT, Li CH, et al. The UCSC Genome Browser database: 2014 update. Nucleic Acids Res. 2014; 42:D764-770.

45. Rassen JA, Shelat AA, Myers J, Glynn RJ, Rothman KJ and Schneeweiss S. One-to-many propensity score matching in cohort studies. Pharmacoepidemiol Drug Saf. 2012; 21:69-80.

46. Ho DE, Imai $\mathrm{K}$, King $\mathrm{G}$ and Stuart EA. MatchIt: Nonparametric Preprocessing for Parametric Causal Inference. J Stat Softw. 2011; 42.

47. Bolstad BM, Irizarry RA, Astrand M and Speed TP. A comparison of normalization methods for high density oligonucleotide array data based on variance and bias. Bioinformatics. 2003; 19:185-193.

48. Hakimi AA, Ostrovnaya I, Reva B, Schultz N, Chen YB, Gonen M, Liu H, Takeda S, Voss MH, Tickoo SK, Reuter VE, Russo P, Cheng EH, Sander C, Motzer RJ, Hsieh JJ, et al. Adverse outcomes in clear cell renal cell carcinoma with mutations of 3 p2 1 epigenetic regulators BAP1 and SETD2: a report by MSKCC and the KIRC TCGA research network. Clin Cancer Res. 2013; 19:3259-3267.

49. Subramanian A, Tamayo P, Mootha VK, Mukherjee S, Ebert BL, Gillette MA, Paulovich A, Pomeroy SL, Golub TR, Lander ES and Mesirov JP. Gene set enrichment analysis: a knowledge-based approach for interpreting genomewide expression profiles. Proc Natl Acad Sci U S A. 2005; 102:15545-15550. 